\title{
Properties of PMMA/clay nanocomposites prepared using various compatibilizers
}

\author{
Manish Kumar ${ }^{1}$, S Arun², Pradeep Upadhyaya ${ }^{3}$ and G Pugazhenthi ${ }^{1 *}$
}

\begin{abstract}
Background: In the fabrication of polymer/clay nanocomposites, the compatibilizer plays a vital role in altering the properties of nanocomposite systems. The present work primarily deals with the development of poly(methyl methacrylate) (PMMA)/clay nanocomposites containing different compatibilizers (PP-g-MA, PE-g-MA and PS-g-MA) with 5 wt.\% nanoclay.

Methods: The various PMMA nanocomposites were prepared by melt intercalation method using twin screw extruder followed by injection moulding to make specimens for mechanical testing.

Results: The mechanical, thermal and morphological properties of nanocomposites were evaluated by tensile test, impact, hardness, thermogravimetric analysis (TGA), differential scanning calorimetry (DSC), X-ray diffraction (XRD) and transmission electron microscopy (TEM). The intercalated structure of the PMMA nanocomposites is validated by XRD and TEM analysis. The results are found to be good agreement with each other.

Conclusions: The TGA data demonstrate that PMMA nanocomposites exhibit enhanced thermal stability of $22-36^{\circ} \mathrm{C}$ with respect to pure PMMA, at 50\% weight loss is considered as point of reference. The PMMA nanocomposite prepared with PS-g-MA compatibilizer promotes adequate interface adhesion between the nanoclay and polymer matrix. As a result, PMMA-5-PS sample displays improved mechanical properties over PMMA-5-PP and PMMA-5-PE samples. The maximum improvement of tensile strength, Young's modulus and hardness for the PMMA-5-PS nanocomposites over PMMA-5-PE is estimated to be 8,2 and $26 \%$, respectively.
\end{abstract}

Keywords: PMMA; Compatibilizer; Clay; Hardness; XRD; TGA

\section{Background}

Polymer nanocomposites have received considerable interest, both in academia and in industry, because of their enhanced properties at very low loading levels compared with conventional polymer composites. They generally display superior properties such as mechanical, thermal, gas-barrier property, flame retardant and dimensional stability with respect to conventional filler composites. These improved properties are often obtained by the incorporation of nanofillers with preferably less than $100 \mathrm{~nm}$ in size (Ray and Okamoto 2003). Several nanoparticulates such as clay minerals, carbon nanotubes, silica and $\mathrm{TiO}_{2}$ nanoparticles are generally used in altering the physical, mechanical and thermal properties of polymers (Ahmad et al. 2006; Zheng et al. 2005; Lee et al. 2006; Etienne et al. 2007).

\footnotetext{
* Correspondence: pugal@iitg.ernet.in

${ }^{1}$ Department of Chemical Engineering, Indian Institute of Technology

Guwahati, Guwahati, India

Full list of author information is available at the end of the article
}

PMMA is an atactic, amorphous and optically transparent material with high strength, excellent dimensional stability and outdoor weather performance. However, its application is restricted at higher temperature due to its relatively poor thermal stability. To overcome this problem, nanotechnology is implemented in this field, in order to further improve the properties of PMMA. In such technology, montmorillonite (MMT) modified with organic modifier, also known as organoclay, is impregnated into polymer matrix. To obtain nanoscale dispersion of the organoclay, the modification of PMMA matrix with polar molecules is recommended prior to organoclay incorporation. Compatibilizers are generally added in the nanocomposites in order to improve the interfacial adhesion between organoclay and polymer matrix that generally results in enhanced mechanical and morphological properties (Lim et al. 2006; Chow et al. 2005).

Various methods have been employed for the synthesis of polymer nanocomposites with better properties such as solvent blending, in situ polymerization and melt- 
intercalation technique (Krajnc and Sebenik 2009; Li et al. 2008; Fu and Naguib 2006). Melt intercalation has been widely accepted and an economical method for industrial applications. The effect of various compatibilizers on polymer matrix or blends has been studied by numerous authors (Shanks and Cerezo 2012; Dayma et al. 2011; Jiang et al. 2003; Lu et al. 2004, Zhu et al. 2008). The HDPE and nitrile copolymer nanocomposites with organoclay were synthesized by solution blending method and found that greater dispersion was obtained in nitrile copolymer matrix (Jeon et al. 1998). Kim et al. (2007a, 2007b) developed PP/clay nanocomposites. They reported that the aspect ratio of clay decreased when the clay content increased and the aspect ratio increased with an increase in the PP-g-MA content. Kitayama et al. (1991) prepared triblock copolymer of PMMA and polyisobutylene by anionic polymerization and reported that block copolymer formed was rigid spherical particles, which can be used as elastomer. Kouini and Serier (2012)) found that the impact property increased with the incorporation of PP-g-MA in PP/PA66 nanocomposites. TPO/PP-g-MA/MMT nanocomposites prepared by Kim et al. (2007a, 2007b) revealed that the modulus and yield strength enhanced by increasing PP-g-MA/organoclay ratios. Zhou et al. (2007) prepared the PMMA/PVC by melt blending using PB-g-MMA as impact modifier. The result clearly indicated that the sample broke in brittle mode when the matrix was PMMA rich, while in PVC-rich system, ductile fracture occurred. Lai et al. (2009) fabricated PP/nanocomposites with two different compatibilizers (POE-g-MA and PP-g-MA) by melt mixing method. They found that PP-g-MA compatibilized system conferred higher tensile strength, modulus and optical properties as compared to POE-g-MA compatibilized system. Wang et al. (2013) reported the development of PP nanocomposites using PP-g-MA by compression method. The results suggested that MCM-41 and SBA-15 exhibited favourable effect on flammability and tensile properties of PP nanocomposites. Lin et al. (2013) studied $\beta$-PP/PA6 blends, and the results indicated that the addition of PP-g-MA resulted in PP-g-MA graft copolymer, which improved the interfacial adhesion and reduced the sizes of PA6 domains. Lee et al. (2005) synthesized the PE/clay nanocomposites containing PP-g-MA by melt-intercalation method. They found that tensile and gas barrier properties were improved at $7 \%$ clay loading. Zhao et al. (2008) reported that the $\mathrm{Tg}$ and thermal decomposition temperature of PMMA nanocomposite were enhanced by 23 and $93{ }^{\circ} \mathrm{C}$, respectively, in the presence of octavinyl-polyhedral oligomeric silseoquioxane (OV-POSS). In the study of Wang et al. (2011), the addition of PMMA/MCM-41 filler and PPg-MA in PP nanocomposites showed better tensile and impact properties. Quintanilla et al. (2006) prepared PP/
MMT nanocomposites with different grafting efficiency of PP-g-MA. The result clearly indicated that PP/Cloisite 20A nanocomposites with higher efficiency PP-g-MA (2.0) exhibited better tensile and impact properties as compared to Cloisite $30 \mathrm{~B}$ and neat clay. The incorporation of POEg-MA in PET/PP blends considerably improved mechanical properties such as elongation at break and impact strength (Chiu and Hsiao 2006). It is very clear from the literature review that the compatibilizer plays a major role in improving the properties of nanocomposite systems. Hence, it is essential to examine the role of various compatibilizers on the properties of PMMA nanocomposites.

To our best knowledge, no researchers have investigated the influence of compatibilizers on the properties of PMMA nanocomposites prepared using nanoclay modified with $15-35 \%$ octadecylamine and $0.5-5 \mathrm{wt} . \%$ aminopropyltriethoxysilane. Thus, the aim of the present work is to investigate the role of various compatibilizers (PP-g-MA, PE-g-MA, PS-g-MA) on the properties of PMMA/clay nanocomposites developed by melt blending method. The morphological, thermal and mechanical properties of the nanocomposites are evaluated using various techniques.

\section{Methods}

\section{Materials}

PMMA (IG 840) used in this study was a commercial product from LG Polymers, South Korea. The melt flow index (MFI at $230{ }^{\circ} \mathrm{C}$ and $3.8 \mathrm{~kg}$ load) and specific gravity of PMMA were $5.8 \mathrm{~g} / 10 \mathrm{~min}$ and 1.18 , respectively. Nanoclay (Nanomer 1.31 PS, MMT clay surface modified with $15-35 \%$ octadecylamine and 0.5-5 wt.\% aminopropyltriethoxysilane), polypropylene-grafted maleic anhydride (PP-g-MA), polyethylene-grafted maleic anhydride (PE-g-MA) and polystyrene-block-poly(ethyleneran-butylene)-block-polystyrene-graft-maleic anhydride (PS-g-MA) were purchased from Sigma-Aldrich, USA.

\section{Preparation of PMMA/clay nanocomposites}

Prior to melt intercalation, PMMA pellets and organoclay were dried in a vacuum oven at 80 and $65^{\circ} \mathrm{C}$, respectively, for $12 \mathrm{~h}$. PMMA nanocomposites containing $5 \mathrm{wt} . \%$ of organoclay and $5 \mathrm{wt} . \%$ of compatibilizer were prepared by melt intercalation technique in a twin screw extruder (Make: Specifiq Engineering and Automats, Vadodara, India; Model-ZV-20 HI TORQUE). In a typical experiment, PMMA, organoclay and different compatibilizers were fed into the extruder and the obtained extrudate was quenched in water at room temperature. Subsequently, the extrudate was cut into pellets and then dried before being injection moulded (JSW, Japan; Model-180 High Pressure) at $180-250{ }^{\circ} \mathrm{C}$ to make specimens for mechanical testing. Hereafter, the nanocomposites prepared using PP-g-MA, PE-g-MA and PS- 
g-MA along with 5 wt.\% nanoclay is referred as PMMA5-PP, PMMA-5-PE and PMMA-5-PS. Pure PMMA sample was also prepared by a similar method in the absence of compatibilizer and clay.

\section{Measurements}

Fourier transform infrared spectroscopy (FTIR)

The FTIR analysis of different nanocomposites was performed on Shimadzu Fourier transform infrared spectroscopy to confirm the different functional peaks in nanocomposites.

\section{$X$-ray diffraction analysis}

X-ray diffraction (XRD) profile of organoclay and various PMMA nanocomposite samples were measured under air at room temperature by AXS D8 ADVANCE Fully Automatic Powder X-ray Diffractometer (Bruker) with $\mathrm{Cu}-\mathrm{K} \alpha$ radiation $(\lambda=0.15406 \mathrm{~nm})$ and $\mathrm{Ni}$ filter. The patterns were recorded for $2 \theta$ range from $1^{\circ}-50^{\circ}$ with $0.05 \mathrm{~s}^{-1}$ scan speed.

\section{Transmission electron microscopy}

The transmission electron microscopy (TEM) image of PMMA nanocomposites were obtained on JOEL, ModelJEM-2100 transmission electron micro analyser with an accelerating voltage of $200 \mathrm{KV}$.

\section{Mechanical properties}

The tensile properties were measured based on ASTM D 638 at a crosshead speed of $5 \mathrm{~mm} / \mathrm{min}$ using INSTRON (M 3382, UK) universal testing machine. The flexural strength and modulus of PMMA nanocomposites were measured according to ASTM D790. The test was carried out on INSTRON (M 3382, UK) universal testing machine. A rectangular bar was placed on the 3-point bending configuration at $1.45 \mathrm{~mm} / \mathrm{min}$ deformation rate. Both the tests were performed at $23 \pm 2{ }^{\circ} \mathrm{C}$ and $50 \pm 5 \%$ relative humidity. Five samples were tested for each composition, and the average value was reported. Impact strength measurements were performed using an impactometer $(\mathrm{M} / \mathrm{s}$ Tinius Olsen, USA). The hardness (Shore D) of the nanocomposites was measured according to ASTM D2240. Ten readings were taken at different regions for each sample, and average value was reported.

\section{DSC analysis}

Differential scanning calorimetry (DSC) was performed on a Metler Toledo-1 series to evaluate the glass transition temperature (Tg) of the PMMA nanocomposites. Samples were heated from 25 to $250{ }^{\circ} \mathrm{C}$ at a rate of $10{ }^{\circ} \mathrm{C} \mathrm{min}{ }^{-1}$ under nitrogen atmosphere.

\section{Thermo gravimetric analysis}

The thermogravimetric analysis (TGA) was recorded on Mettler Toledo thermoanalyser under a nitrogen atmosphere at a heating rate of $10{ }^{\circ} \mathrm{C} / \mathrm{min}$ from room temperature to $700{ }^{\circ} \mathrm{C}$.

\section{Results and discussion FTIR}

Figure 1 represents the FTIR spectra of different compatibilizers (PE-g-MA, PP-g-MA and PS-g-MA) used in this study. The $\mathrm{CH}$ - asymmetric (2930-2970 $\mathrm{cm}^{-1}$ ) and symmetric stretching (2840-2860 $\left.\mathrm{cm}^{-1}\right)$ are clearly seen in polyolefin-based compatibilizers. The characteristic peak of grafted anhydride, which is too small to observe, is found at $1843 \mathrm{~cm}^{-1}$ (Kouini and Serier 2012; Wang et al. 1999). In PS-g-MA compatibilizer, the band present at the $671 \mathrm{~cm}^{-1}$ is the $\delta_{\mathrm{c}=\mathrm{c}}$ of the phenyl group (Li et al. 2002).

In Fig. 2, the FTIR spectrum of nanoclay displays that the peak exhibited at $1046 \mathrm{~cm}^{-1}$ is attributed to the $\mathrm{Si}-\mathrm{O}$ stretching vibration of clay. For nanoclay, two peaks were observed in between 3300 and $3700 \mathrm{~cm}^{-1}$, which corresponds to $-\mathrm{OH}$ stretching vibration. The first peak at $3630 \mathrm{~cm}^{-1}$ is assigned to isolated $\mathrm{OH}$ groups, while the other found at $3246 \mathrm{~cm}^{-1}$ is involved in hydrogen bonding. Three subsequent peaks were recorded at 2922, 2849 and $1465 \mathrm{~cm}^{-1}$, which denotes $\mathrm{CH}_{2}$ asymmetric stretching, symmetric stretching and in-plane scissoring vibrations, respectively. The peaks appeared at 917, 750, 530 and $458 \mathrm{~cm}^{-1}$ that correspond to $\mathrm{AlAlOH}, \mathrm{AlMgOH}, \mathrm{Al}-\mathrm{O}$ and $\mathrm{Mg}-\mathrm{O}$ bending vibration, respectively (Madejová 2003). The absorption band at $1612 \mathrm{~cm}^{-1}$ resembles to the bending vibration mode of hydrated water molecules and weakly bonded water molecules (Manoratne et al. 2006).

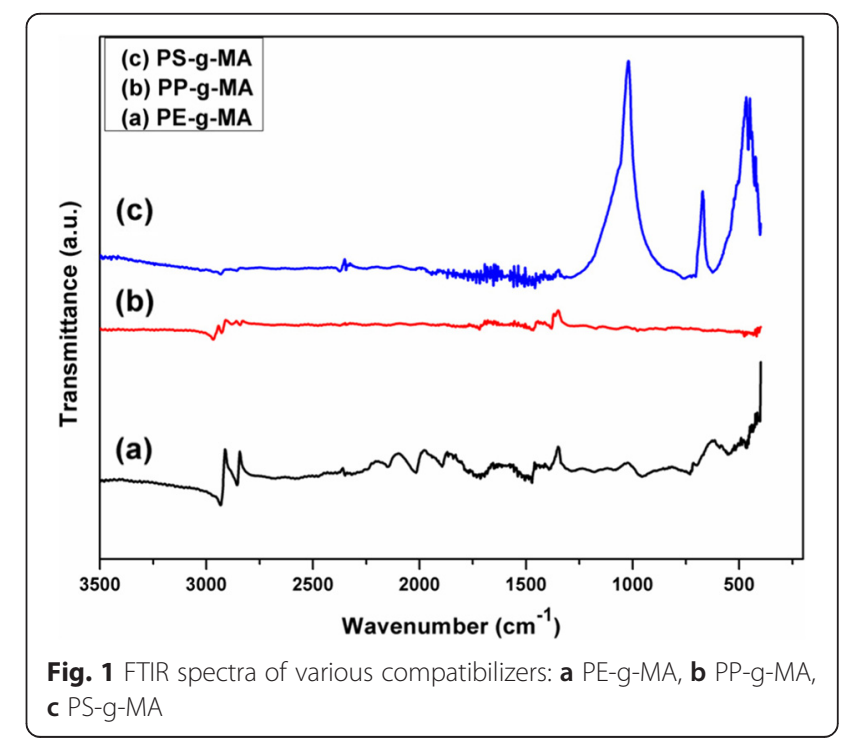




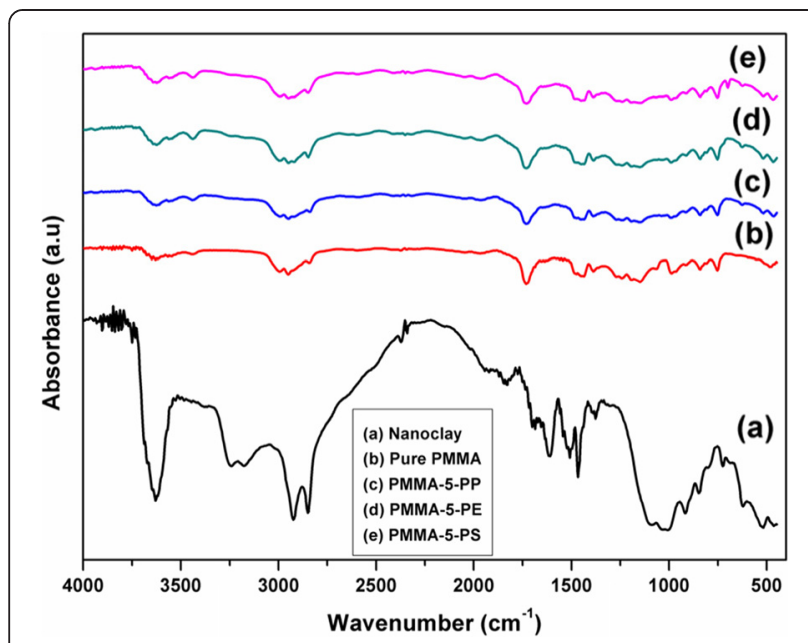

Fig. 2 FTIR spectra of a nanoclay, b pure PMMA, c PMMA-5-PE, d PMMA-5-PP e and PMMA-5-PS

The FTIR of PMMA and its nanocomposites show a characteristic peak at $1731 \mathrm{~cm}^{-1}$, which denotes the $>\mathrm{C}=$ $\mathrm{O}$ group present in the polymer. The band at $986 \mathrm{~cm}^{-1}$ denotes the $-\mathrm{C}-\mathrm{H}$ bending of polymer chain. The peak observed at $1436 \mathrm{~cm}^{-1}$ corresponds to $-\mathrm{O}-\mathrm{CH}_{3}$ deformation of PMMA. The band exhibited at $2994 \mathrm{~cm}^{-1}$ is due to the ester methyl stretching vibrations. The peak appeared at $2950 \mathrm{~cm}^{-1}$ corresponding to the asymmetric stretching vibration of $-\mathrm{CH}_{3}$ group. A very clear and sharp peak is noticed in the range of $3438-3442 \mathrm{~cm}^{-1}$ that shows the intra-molecular hydrogen bonding between nanoclay and PMMA Mohanty and Nayak (2010). As the pure polymer and different composite samples mainly consist of PMMA, it is observed that there is no much difference among composites prepared with various compatibilizers (Fig. 2c-e). Mohanty and Nayak (2010) also reported similar type of result with PMMA-g-MA and Closite 30B clay.

\section{XRD analysis}

$\mathrm{XRD}$ is a most useful technique for the measurement of d-spacing of ordered intercalated and exfoliated nanocomposites. The intercalated nanocomposite with increased d-spacing denotes that polymer has entered the clay gallery while in exfoliated nanocomposites, no peak is noticed recommending that a considerable amount of polymer has inserted the gallery space and expanding the clay layers so far (Morgan and Gilman 2003). The XRD pattern of nanoclay, pure PMMA and its nanocomposites in the $2 \theta$ range of $1^{\circ}-50^{\circ}$ is shown in Fig. 3.

The main diffraction peak for nanoclay, pure PMMA, PMMA-5-PE, PMMA-5-PP and PMMA-5-PS sample, is obtained at $2 \theta$ value of $4.15^{\circ}, 13.34^{\circ}, 2.74^{\circ}, 2.54^{\circ}$ and $2.70^{\circ}$, respectively. The $d_{001}$ spacing is calculated from peak positions using Bragg's law: $\lambda=2 d \sin \theta$, where $\lambda$ is the X-ray wave length (1.5406 $\AA$ ). The basal spacing of

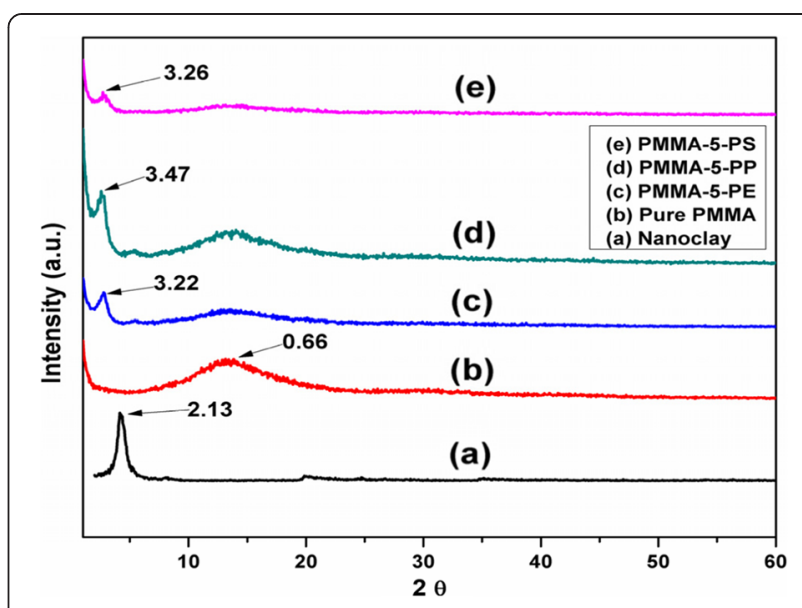

Fig. 3 XRD pattern of a nanoclay, b pure PMMA, c PMMA-5-PE, d PMMA-5-PP and e PMMA-5-PS

the $\mathrm{d}_{001}$ peak of organically modified nanoclay is estimated as $2.13 \mathrm{~nm}$. In the nanocomposites, a large broad hump is originated from the PMMA matrix. The $\mathrm{d}$ spacing $\left(\mathrm{d}_{001}\right)$ value of PMMA-5-PE, PMMA-5-PP and PMMA-5-PS is found to be $3.22,3.47$ and $3.26 \mathrm{~nm}$, respectively. This clearly reveals that nanoclay layers have been introduced in the nanocomposites as a single polymer chain enters between the silicate layers, and a tactoid morphology results with alternating polymeric and inorganic layers. The diverse $d$-spacing value obtained for the PMMA nanocomposite with different compatibilizer materials is probably due to the amount of polymer penetrated between the clay platelets and the interaction between a particular compatibilizer with PMMA matrix.

\section{Transmission electron microscopy (TEM)}

In addition to XRD investigations, TEM analysis of the PMMA nanocomposites was performed to delineate the dispersion status of nanoclay in the PMMA matrix. The TEM images of PMMA nanocomposites with different compatibilizer are demonstrated in Fig. 4. The dark lines (stacked silicate platelets) denote clay tactoids, and the rest of the area represents organic matrix. The extent of exfoliation and intercalation completely depends on the hydrophilicity of the compatibilizer and the chain length of the organic modifier in the clay (Wang et al. 2001). All the images exhibit intercalated structure, which is in agreement with XRD results as shown in Fig. 3. In the PMMA-5-PP sample, four to five layers of nanoclay are stacked together, which leads to tactoid structure. However, it is clearly visible from the image of PMMA-5-PE sample (Fig. 4b) that a small amount of PMMA enters into the gallery spacing between the clay platelets resulting in an intercalated structure. The PMMA-5-PS nanocomposite has mixed morphological structure, i.e. a combination of tactoids and exfoliated particles. 

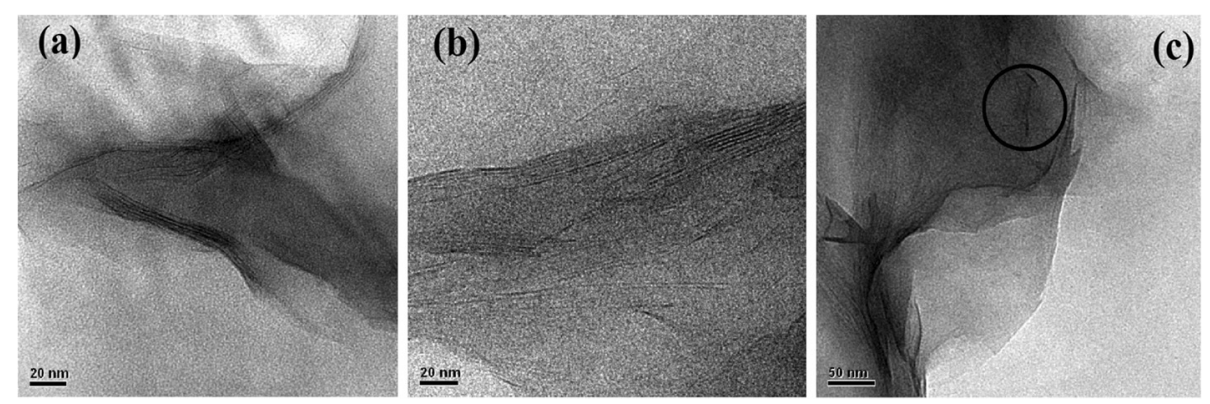

Fig. 4 TEM images of a PMMA-5-PP, b PMMA-5-PE and c PMMA-5-PS

\section{Tensile properties}

Figure 5 shows the role of different compatibilizer on the tensile properties of PMMA. In general, an addition of clay increases the reinforcement of polymer matrix that results in enhanced mechanical properties. It is observed from Fig. 5 that the PMMA nanocomposites prepared with different compatibilizers display enhanced tensile modulus with respect to pure PMMA. In comparison with pure PMMA, the enhancement of modulus is found to be 16, 17, and $20 \%$ for PMMA-5-PP, PMMA5-PE and PMMA-5-PS, respectively. This clearly indicates that there is an effective stress transfer from organoclay to polymer matrix in the presence of high aspect ratio nanoscale platelets. It is also observed that polystyrene-based compatibilizer demonstrates higher modulus when compared with PE-g-MA compatibilizer. It is presumed that both polystyrene and PMMA are amorphous in nature and hence, there may be good miscibility between two polymers that results in increased modulus over PMMA5-PE and PMMA-5-PP nanocomposites. Similar observations were obtained by Mohanty and Nayak (2010) for PMMA-g-MA nanocomposites based on Cloisite $30 B$ clay. It is noteworthy to mention that even though

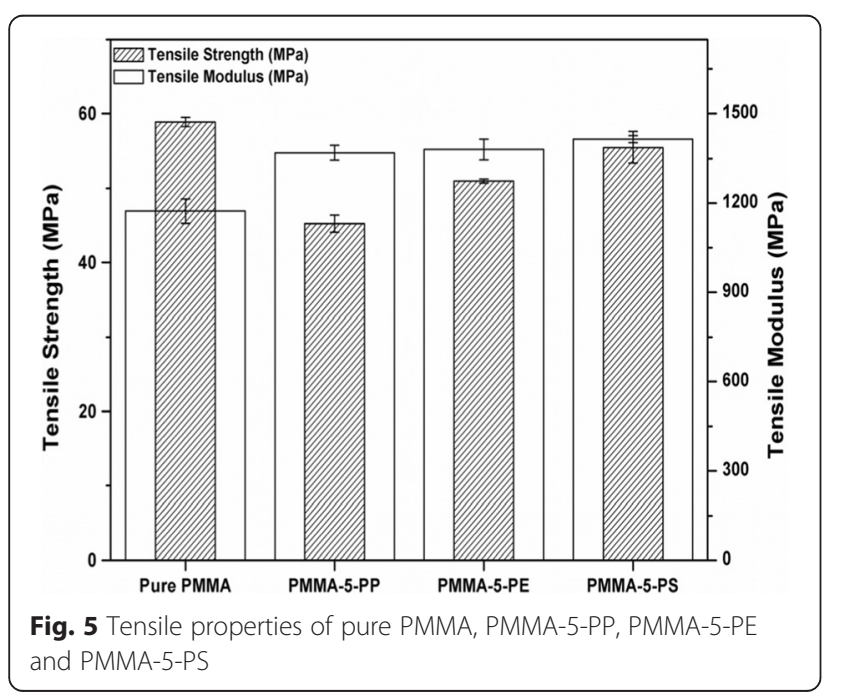

tensile strength reduced slightly after incorporation of nanoclay, modulus is constantly increased. Similar findings were also obtained for polystyrene (Lee et al. 2009) and polyurethane (Chung et al. 2008) containing organoclay.

It is clear from Fig. 5 that PMMA nanocomposites demonstrate slightly lower tensile strength as compared to pure PMMA. It is known that PMMA is brittle in nature to some extent, and the addition of nanoclay particles provides further brittleness characteristics in the amorphous polymer, thus leading to a slight decrease in tensile strength. It is also observed that tactoid structure present in the polymer matrix (see Fig. 4) leads to lower tensile strength. The PMMA-5-PS nanocomposite shows the tensile strength of $55.5 \mathrm{MPa}$ by the incorporation of PS-g-MA compatibilizer, which is higher than that of PMMA-5-PP and PMMA-5-PE samples. One of the main reasons is that both polystyrene and PMMA are amorphous in nature. Hence, there may be a possibility that PS makes good compatibility with PMMA resulting to enhanced tensile strength over other composites.

\section{Flexural properties}

The influence of different compatibilizers on the flexural properties is depicted in Fig. 6. The PMMA-5-PP, PMMA-5-PE and PMMA-5-PS samples have the flexural modulus of 4064, 3092 and $3561 \mathrm{MPa}$, respectively, whereas the pure PMMA sample possesses the flexural modulus of $3688 \mathrm{MPa}$. The PMMA-5-PP nanocomposite shows $10 \%$ enhanced modulus when compared with pure PMMA. This elucidates that PP-g-MA provides better distribution of silicate platelets of nanoclay in the polymer matrix and as a result, stiffness of the PMMA5-PP nanocomposite is improved. The reduced modulus in the nanocomposite may be due to the agglomeration of nanoclay in the PMMA matrix. The degree of intercalation/exfoliation, distribution and orientation of organoclay platelets in the direction of flow in PMMA nanocomposites also play a major role in ascertaining the flexural modulus (Shah 2007). Nevertheless, the flexural modulus of the PMMA-5-PS sample is almost same 


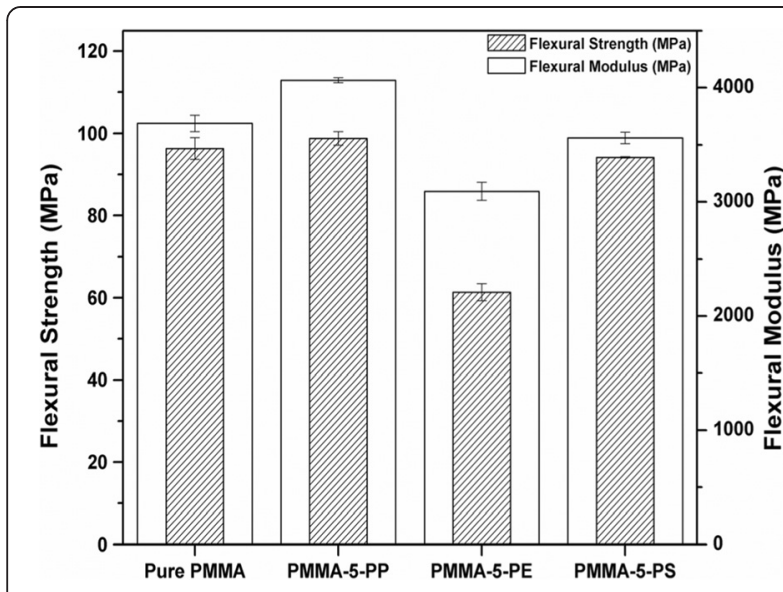

Fig. 6 Flexural properties of pure PMMA, PMMA-5-PP, PMMA-5-PE and PMMA-5-PS

as pure PMMA indicating that PS-g-MA compatibilizer makes good bonding with PMMA matrix when compared with PE-g-MA. The obtained results are in good agreement with polypropylene-based nanocomposites using PP-g-MA as a compatibilizer (Kim et al. 2007a, 2007b). Similarly, the flexural strength of the PMMA5-PE sample is lower with respect to pure PMMA, which is assumed due to the aggregation of nanoclay arises by filler-filler interaction. On the other hand, the addition of PS-g-MA compatibilizer improves the flexural strength of the PMMA-5-PS nanocomposite in comparison with PMMA-5-PE sample. It is believed that the presence of compatibilizer and nanoclay increases the fracture energy and provides a strong interfacial shear stress. Therefore, the applied stress is expected to be easily transferred from the polymer matrix onto the organoclay particles resulting in an enhancement of the mechanical properties. The PMMA-5PS sample exhibits $\sim 53 \%$ improvement in flexural strength with respect to PMMA-5-PE nanocomposite.

\section{Impact strength}

The impact strength of PMMA nanocomposites with nanoclay and different compatibilizer are shown in Fig. 7. It can be seen from the graph that impact energy of different PMMA nanocomposites reduces as compared to pure PMMA. The reduction in impact strength is presumably due to the partially exfoliated nanoclay platelets in polymer matrix. The PMMA-5-PE and PMMA-5-PP nanocomposite exhibit 44 and $56 \%$ lower impact energy with respect to pure PMMA, respectively. It is observed from these results that polyolefin-based compatibilizers are not much efficient to improve the reinforcing properties of the polymer nanocomposites. It is found that immobilization of macromolecular chains is increased by the addition of nanoclay in polymer matrix. Therefore, the

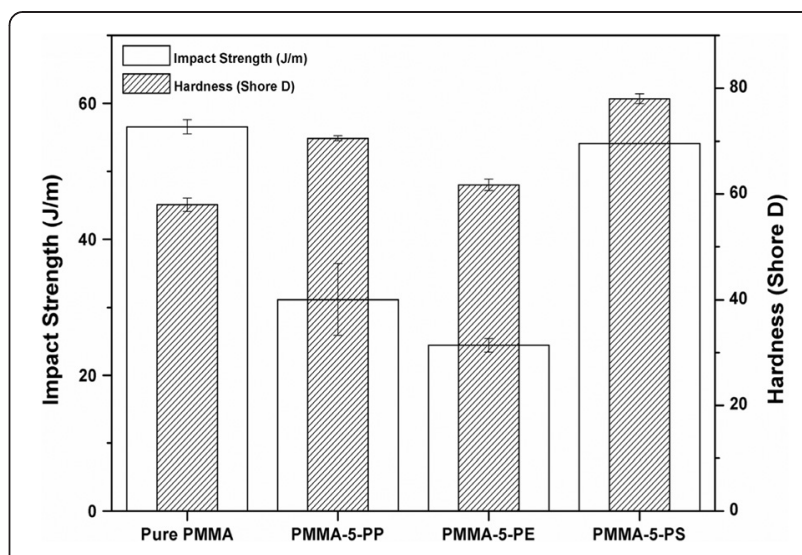

Fig. 7 Impact strength and hardness of pure PMMA, PMMA-5-PP, PMMA-5-PE and PMMA-5-PS

brittleness property of PMMA is further increased, which might be one of the main reasons for reduced impact strength. It is also noticed that the movement of nanoparticles in polymer nanocomposites is constrained, as a result unable to provide additional energy dissipating mechanism. Thus, during impact test, the nanocomposites absorb a smaller amount of energy through deformation and breaks easily (Mohanty and Nayak 2010). The PMMA-5-PS has impact energy of $54.15 \mathrm{~J} / \mathrm{m}$ and it is about $4.31 \%$ lower than the pure PMMA. It is also noticed from the mechanical properties that PMMA-5-PS shows very close property to pure PMMA. As discussed earlier, polystyrene is amorphous in nature and may have good compatibility with PMMA matrix, which is also amorphous. As a result of good blending, the impact strength of PMMA-5-PS is close to pure PMMA.

\section{Hardness}

Figure 7 represents the Shore D hardness (ASTM D2240) of pure PMMA and its nanocomposites. The hardness of PMMA nanocomposites increases with incorporation of nanoclay and compatibilizer. The average value of the Shore D hardness is observed to be 58, 62, 70 and 78 for pure PMMA, PMMA-5-PE, PMMA-5-PP and PMMA-5PS nanocomposites, respectively. All the nanocomposites exhibit better hardness over pure PMMA. The increase in the hardness is due to the presence of clay platelets in the polymer matrix. The clay platelets adequately restrict the indentation and thus enhance the hardness of the nanocomposites. It is noteworthy to mention that improvement of hardness for PMMA-5-PS sample is significant in comparison with PMMA-5-PP and PMMA5-PE. PMMA-5-PS nanocomposite demonstrates a maximum improvement of Shore D hardness of $34 \%$ over pure PMMA. 


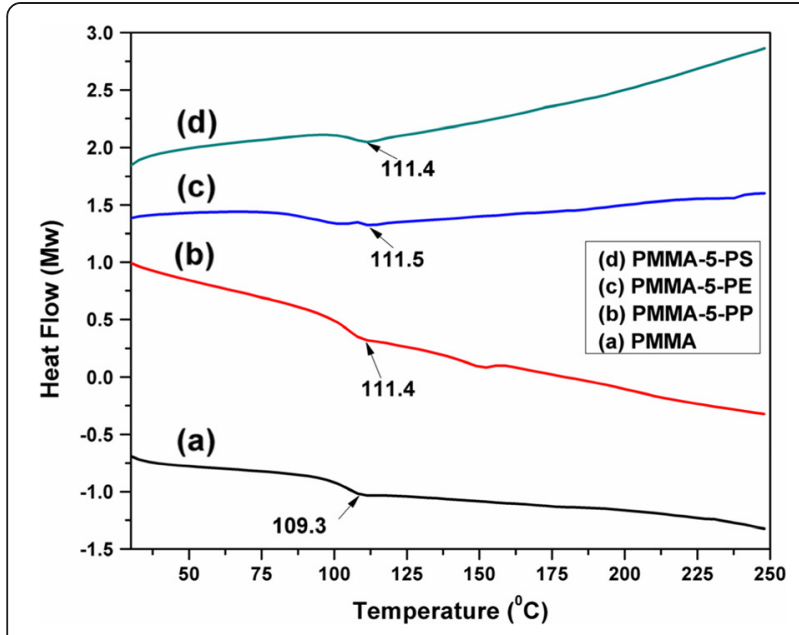

Fig. 8 DSC curves of a PMMA, b PMMA-5-PP, c PMMA-5-PS and d PMMA-5-PS

\section{Differential scanning calorimetry (DSC)}

The DSC study of pure PMMA and its nanocomposites has been carried out in order to examine the mobility of PMMA chains in terms of its $\mathrm{Tg}$ (glass transition temperature) in the clay layers, and the results are displayed in Fig. 8. The glass transition temperature is determined at the inflection point between the onset and the end-set temperatures. The DSC graph exhibits the presence of second-order transition corresponding to the Tg of pure PMMA matrix around $109.3^{\circ} \mathrm{C}$. However, there is no first-order transition, which indicates the absence of melting temperature, thus confirming amorphous characteristics of the matrix polymer. The $\mathrm{Tg}$ of PMMA-5-PP, PMMA-5-PE and PMMA-5-PS nanocomposite is found to be $111.4,111.5$ and $111.4{ }^{\circ} \mathrm{C}$, respectively. This demonstrates that nanocomposites exhibit marginal improvement in $\mathrm{Tg}$ of about $2{ }^{\circ} \mathrm{C}$ as compared to pure PMMA. The DSC isotherm also shows that compatibilizers improved the bonding between the nanoclay and polymer matrix, which results in enhanced glass transition temperature. The $\mathrm{Tg}$ is altered by the presence of high surface area nanoclay in the polymer matrix. The segmental motions of the polymer chains are restricted at the organic-inorganic interface; as a result, $\mathrm{Tg}$ has improved for nanocomposites. The confinement of polymer chains between the nanoclay layers and nanoclay surfacepolymer interaction are other reasons for enhanced glass transition temperature. Unnikrishnan et al. (2011) also reported improvement in thermal stability for PMMA/clay nanocomposites prepared by melt intercalation method.

\section{Thermo gravimetric analysis (TGA)}

TGA is used to study the thermal degradation and stability of the polymer. The incorporation of clay is known to augment the thermal stability of polymers. The TGA

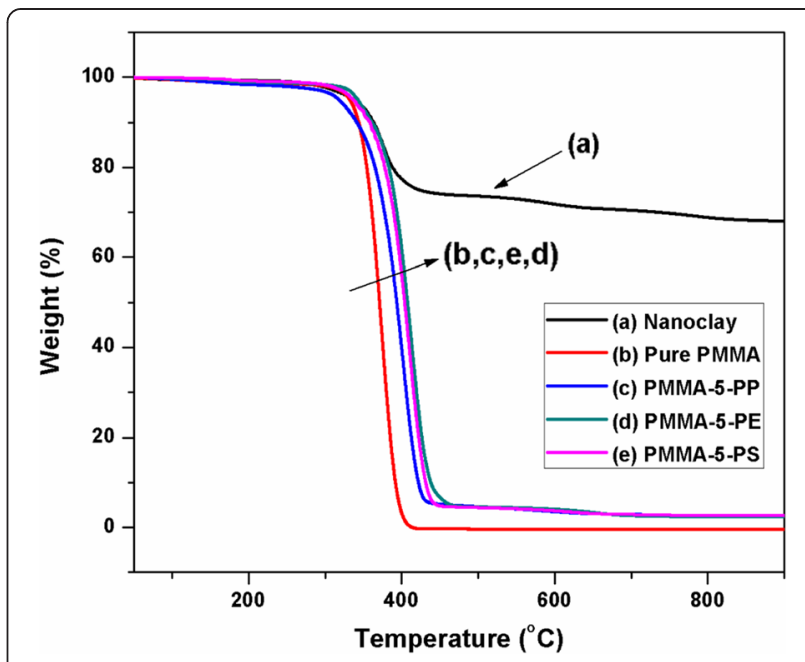

Fig. 9 TGA profile of a nanoclay, b pure PMMA, c PMMA-5-PP, d PMMA-5-PE and e PMMA-5-PS

results of nanoclay, pure PMMA and its nanocomposites are represented in Fig. 9. The TGA graph of nanoclay shows that the total weight loss of about $30 \%$ occurs between 50 and $800{ }^{\circ} \mathrm{C}$. The weight loss between 300 and $450{ }^{\circ} \mathrm{C}$ is due to the degradation of organic modifier present in the clay. The parameters that are important from TGA curves are the onset of degradation, which is usually taken as the temperature at which $10 \%$ degradation occurs $\left(\mathrm{T}_{10} \%\right)$ and the midpoint temperature of degradation $\left(\mathrm{T}_{50} \%\right)$. When $10 \%$ weight loss is selected as a point of comparison, the decomposition temperature of pure PMMA, PMMA-5-PP, PMMA-5-PE and PMMA-5PS is found to be $343.6,341.3,361.2$ and $358.7^{\circ} \mathrm{C}$, respectively. The result clearly explains that the degradation of the nanocomposites takes place at higher temperatures than that of pure PMMA in the presence of nanoclay and

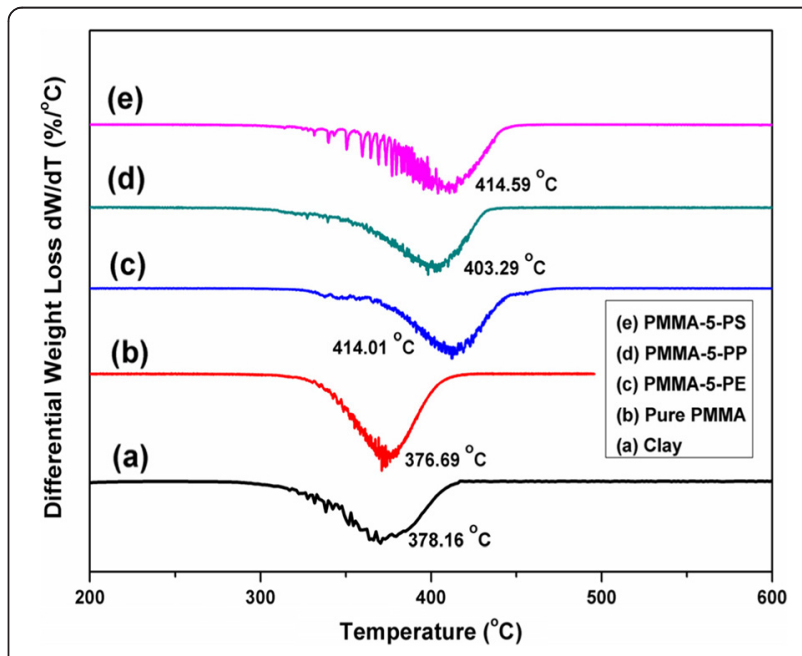

Fig. 10 TGA derivative of a nanoclay, b pure PMMA, c PMMA-5-PP, d PMMA-5-PE and e PMMA-5-PS 
compatibilizer. When $50 \%$ weight loss is chosen as a point of reference, the decomposition temperature of pure PMMA, PMMA-5-PP, PMMA-5-PE and PMMA-5-PS is $371.1,393.4,407.7$ and $403.8{ }^{\circ} \mathrm{C}$, respectively, which is 32 to $36{ }^{\circ} \mathrm{C}$ higher than that of pure PMMA. The enhancement in the thermal stability of PMMA nanocomposites is due to the formation of char that inhibits the out dispersion of the volatile decomposition products as a direct result of the decrease in permeability. This reduction is commonly noticed in the intercalated or exfoliated clay platelets in polymer/organoclay nanocomposites (Unnikrishnan et al. 2011). The PMMA-5-PS nanocomposite shows $27^{\circ} \mathrm{C}$ higher thermal stability as compared to PMMA-g-MA/C30B sample [34] at $50 \%$ weight loss. It can be concluded that all the compatibilizers improve the thermal stability of the PMMA significantly.

The TGA derivative of PMMA nanocomposites is demonstrated in Fig. 10. The peak indicates the temperature $\left(\mathrm{T}_{\max }\right)$ at a maximum rate of degradation. The entire first TGA derivative curves for PMMA nanocomposites are shifted towards the right side of pure PMMA, indicating enhanced thermal stability. The maximum degradation temperature for pure PMMA is $369.69{ }^{\circ} \mathrm{C}$ whereas of PMMA-5-PS nanocomposite is $414.59{ }^{\circ} \mathrm{C}$. This indicates $44{ }^{\circ} \mathrm{C}$ improvement in thermal stability that will lead to better service performance of the nanocomposites at an elevated temperature. Similar observations were also reported for polystyrene nanocomposites (Sahu and Pugazhenthi 2011).

\section{Conclusions}

1. PMMA nanocomposites with different compatibilizer have been successfully prepared by melt compounding technique.

2. It is found from the XRD analysis that PMMA-5-PS sample shows a d-spacing of $3.26 \mathrm{~nm}$. The TEM image also demonstrates that PMMA-5-PS nanocomposite possesses partially exfoliated structure.

3. The tensile modulus of nanocomposites increases by the incorporation of compatibilizers, and it is found to be 16, 17 and $20 \%$ higher over pure PMMA for PMMA-5-PP, PMMA-5-PE and PMMA-5-PS, respectively.

4. The hardness (Shore D) is also improved by $34 \%$ for PMMA-5-PS as compared to pure PMMA.

5. TGA study reveals that the entire nanocomposites exhibit enhanced thermal stability when compared with pure PMMA.

6. Among all the materials, PMMA-5-PS nanocomposite display shows optimum mechanical properties.

\section{Competing interests}

The authors declare that they have no competing interests.

\section{Authors' contributions}

Manish Kumar carried out the nanocomposite fabrication and characterization of materials. S. Arun helped in the melt intercalation of polymer nanocomposite using twin screw extruder and tensile measurements. Pradeep Upadhyaya assisted in evaluation of impact test. G. Pugazhenthi guided the entire research work successfully starting from the novel idea, provocative discussion and helpful advice. All authors have read and approved the final manuscript.

\section{Acknowledgements}

We would like to thank the Central Instruments Facility, IIT Guwahati, for helping us to perform TEM analysis. XRD used in this work was financially supported by a FIST grant (SR/FST/ETII-028/2010) from the Department of Science and Technology (DST), Government of India.

\section{Author details}

${ }^{1}$ Department of Chemical Engineering, Indian Institute of Technology Guwahati, Guwahati, India. ${ }^{2}$ Department of Mechanical Engineering, Indian Institute of Technology Guwahati, Guwahati, India. ${ }^{3}$ Central Institute of Plastics Engineering and Technology (CIPET), Ahmedabad, India.

Received: 7 March 2015 Accepted: 11 May 2015

Published online: 03 June 2015

\section{References}

Ahmad, S, Saxena, TK, Ahmad, S, \& Agnihotry, SA. (2006). The effect of nanosized $\mathrm{TiO}_{2}$ addition on poly(methylmethacrylate) based polymer electrolytes. Journal of Power Sources, 159, 205-209. doi:10.1016/j.jpowsour.2006.04.044.

Chiu, HT, \& Hsiao, YK. (2006). Compatibilization of poly(ethylene terephthalate)/ polypropylene blends with maleic anhydride grafted polyethylene-octene elastomer. Journal of Polymer Research, 13, 153-160. doi:10.1007/s10965-005-9020-z.

Chow, WS, Bakar, A, Ishak, ZAM, Kocsis, JK, \& Ishiaku, US. (2005). Effect of maleic anhydride-grafted ethylene-propylene rubber on the mechanical, rheological and morphological properties of organoclay reinforced polyamide 6/polypropylene nanocomposites. European Polymer Journal, 41, 687-696. doi:10.1016/ j.europolymj.2004.10.041

Chung, Y, Cho TK \& Chun, BC. (2008) Dependence of Montmorillonite Dispersion in Nanocomposites on Polymer Matrix and Compatibilizer Content, and the Impact on Mechanical Properties. Fibers and Polymers, 9, 7-14. doi:10.1007/ s12221-008-0002-8

Dayma, N, Satapathy, BK, \& Patnaik, A. (2011). Structural correlations to sliding wear performance of PA-6/PP-g-MA/nanoclay ternary nanocomposites. Wear, 271, 827-836. doi:10.1016/j.wear.2011.03.008.

Etienne, S, Becker, C, Ruch, D, Grignard, B, Cartigny, G, Detrembleur, C, Calberz, C, \& Jerome, R. (2007). Effects of incorporation of modified silica nanoparticles on the mechanical and thermal properties of PMMA. Journal of Thermal Analysis and Calorimetry, 87, 101-104. doi:10.1007/s10973-006-7827-4.

Fu, J, \& Naguib, HE. (2006). Effect of nanoclay on the mechanical properties of PMMA/clay nanocomposites foams. Journal of Cellular Plastics, 42, 325-342. doi:10.1177/0021955X06063517.

Jeon, HG, Jung, HT, Lee, SW, \& Hudson, SD. (1998). Morphology of polymer/ silicate nanocomposites High density polyethylene and a nitrile copolymer. Polymer Bulletin, 41, 107-113. doi:10.1007/s00289005039.

Jiang, C, Filippi, S, \& Magagnini, P. (2003). Reactive compatibilizer precursors for LDPE/PA6 blends. II: maleic anhydride grafted polyethylenes. Polymer, 44, 2411-2422. doi:10.1016/S0032-3861(03)00133-2.

Kim, DH, Fasulo, PD, Rodgers, WR, \& Paul, DR. (2007a). Effect of the ratio of maleated polypropylene to organoclay on the structure and properties of TPO-based nanocomposites. Part I: morphology and mechanical properties. Polymer, 48, 5960-5978. doi:10.1016/j.polymer.2007.08.010.

Kim, DH, Fasulo, PD, Rodgers, WR, \& Paul, DR. (2007b). Structure and properties of propylene-based nanocomposites: effect of PP-g-MA to organoclay ratio. Polymer, 48, 5308-5323. doi:101016/j.polymer.2007.07.011.

Kitayama, T, Nishiura, T, \& Hatada, K. (1991). PMMA-block-polyisobutylene-blockPMMA prepared with $a, \omega$-dilithiated polyisobutylene and its characterization. Polymer Bulletin, 26, 513-520. doi:10.1007/BF01032676.

Kouini, B, \& Serier, A. (2012). Properties of polypropylene/polyamide nanocomposites prepared by melt processing with a PP-g-MAH compatibilizer. Materials and Design, 34, 313-318. doi:10.1016/j.matdes.2011.08.025. 
Krajnc, M, \& Sebenik, U. (2009). Poly(methyl methacrylate)/montmorillonite nanocomposites prepared by bulk polymerization and melt compounding. Polymer Composites, 30, 1678-1686. doi:10.1002/pc.20742.

Lai, SM, Chen, WC, \& Zhu, XS. (2009). Melt mixed compatibilized polypropylene/ clay nanocomposites: part 1 -the effect of compatibilizers on optical transmittance and mechanical properties. Composites: Part A, 40, 754-765. doi:10.1016/j.compositesa.2009.03.006.

Lee, HG, Sung, Y, Lee, YK, Kim, WN, Yoon, HG \& Lee, HS. (2009) Effect of PP-g$\mathrm{MAH}$ on the Mechanical, Morphological and Rheological Properties of Polypropylene and Poly(Acrylonitrile-Butadiene-Styrene) Blends. Macromolecular Research, 17, 417-423. doi:10.1007/BF03218883.

Lee, JH, Jung, D, Hong, CE, Rhee, KY, \& Advani, AG. (2005). Properties of polyethylenelayered silicate nanocomposites prepared by melt intercalation with a PP-g-MA compatibilizer. Composites Science and Technology, 65, 1996-2002. doi:10.1016/ j.compscitech.2005.03.015.

Lee, WJ, Lee, SE, \& Kim, CG. (2006). The mechanical properties of MWNT/PMMA nanocomposites fabricated by modified injection molding. Composite Structures, 76, 406-410. doi:10.1016/j.comp.struct.2005.11.008.

Li, H, Chen, H, Shen, Z, \& Lin, S. (2002). Preparation and characterization of maleic anhydride-functionalized syndiotactic polystyrene. Polymer, 43, 5455-5461. doi:10.1016/S0032-3861(02)00369-5.

Li, Y, Zhang, B, \& Pan, X. (2008). Preparation and characterization of PMMAkaolinite intercalation composites. Composites Science and Technology, 68, 1954-1961. doi:10.1016/j.compscitech.2007.04.003.

Lim, JW, Hassan, A, Rahmat, AR, \& Wahit, MU. (2006). Morphology, thermal and mechanical behaviour of propylene nanocomposites toughened with poly(ethylene-co-octene). Polymer International, 55, 204-215. doi:10.1002/pi.1942.

Lin, Z, Guan, Z, Xu, B, Chen, C, Guo, G, Zhou, J, Xian, J, Cao, L, Wang, Y, Li, M, \& Li, W. (2013). Crystallization and melting behaviour of propylene in $\beta$-PP/polyamide 6 blends containing PP-g-MA. Journal of Industrial and Engineering Chemistry, 19, 692-697. doi:10.1016/j.jiec.2012.10.004.

Lu, C, Guo, S, Wen, L, \& Wang, J. (2004). Weld line morphology and strength of polystyrene/polyamide-6/poly(styrene-co-maleic anhydride) blends. European Polymer Journal, 40, 2565-2572. doi:10.1016/ j.europolymj.2004.06.016.

Madejová, J. (2003). FTIR techniques in clay mineral studies. Vibrational Spectroscopy, 31, 1-10. doi:10.1016/S0924-2031(02)00065-6.

Manoratne, CH, Rajapakse, RMG, \& Dissanayake, MAKL. (2006). Ionic conductivity of poly(ethylene oxide) (PEO)-montmorillonite (MMT) nanocomposites prepared by intercalation from aqueous medium. International Journal of Electrochemical Science, 1, 32-46.

Mohanty, S, \& Nayak, SK. (2010). Effect of organo-modified layered silicates on the properties of poly(methyl methacrylate) nanocomposites. Journal of Thermoplastic Composite Materials, 23, 623-645. doi:10.1177/0892705709356341.

Morgan, AB, \& Gilman, JW. (2003). Characterization of polymer-layered silicate (clay) nanocomposites by transmission electron microscopy and $\mathrm{x}$-ray diffraction: a comparative study. Journal of Applied Polymer Science, 87, 1329-1338. doi:10.1002/app.11884.

Quintanilla, MLL, Valdes, SS, Valle, LFR, \& Miranda, RG. (2006). Preparation and mechanical properties of PP/PP-g-MA/Org-MMT nanocomposites with different MA content. Polymer Bulletin, 57, 385-393. doi:10.1007/s00289-006-0555-x.

Ray, SS, \& Okamoto, M. (2003). Polymer/layered silicate nanocomposites: a review from preparation to processing. Progress in Polymer Science, 28, 1539-1641. doi:10.1016/j.progpolymsci.2003.08.002.

Sahu, B, \& Pugazhenthi, G. (2011). Properties of polystyrene/organically modified layered double hydroxide nanocomposites synthesized by solvent blending method. J Appl Poly Sci, 120, 2485-2495. doi:10.1002/app.33467.

Shah, V. (2007). Handbook of plastic testing and failure analysis of plastic technology (pp. 17-93). New Jersey: John Wiley and Sons.

Shanks, RA, \& Cerezo, FT. (2012). Preparation and properties of poly(propylene-gmaleic anhydride) filled with expanded graphite oxide. Composites: Part A, 43 1092-1100. doi:10.1016/j.compositesa.2012.01.028.

Unnikrishnan, L, Mohanty, S, Nayak, SK, \& Ali, A. (2011). Preparation and characterization of poly(methyl methacrylate)-clay nanocomposites via melt intercalation: effect of organoclay on thermal, mechanical and flammability properties. Materials Science and Engineering A, 528, 3943-3951. doi:10.1016/ j.msea.2011.01.071.

Wang, M, Zhu, X, Wang, S, \& Zhang, L. (1999). Surface pattern in thin poly(styrene-maleic anhydride) film. Polymer, 40, 7387-7396. doi:10.1016/ S0032-3861(99)00008.
Wang, KH, Choi, MH, Koo, CM, Choi, YS, \& Chung, IJ. (2001). Synthesis and characterization of maleated polyethylene/clay nanocomposites. Polymer, 42, 9819-9826. doi:10.1016/S0032-3861(01)00509-2.

Wang, N, Gao, N, Jiang, S, Fang, Q, \& Chen, E. (2011). Effect of different structure MCM-41 fillers with PP-g-MA on mechanical and crystallization performances of polypropylene. Composites: Part B, 42, 1571-1577. doi:10.1016/ j.compositesb.2011.04.012.

Wang, N, Zhang, J, Fang, Q, \& Hui, D. (2013). Influence of mesoporous fillers with PP-g-MA on flammability and tensile behaviour of polypropylene composites. Composites: Part B, 44, 467-471. doi:10.1016/j.compositesb.2012.04.006.

Zhao, C, Yang, X, Wu, X, Liu, Z, Wang, X, \& Lu, L. (2008). Preparation and characterization of poly(methyl methacrylate) nanocomposites containing octavinyl polyhedral oligomeric silsesquioxane. Polymer Bulletin, 60, 495-505. doi:10.1007/s00289-008-0887-9.

Zheng, X, Jiang, DD, \& Wilkie, CA. (2005). Methyl methacrylate oligomericallymodified clay and its poly(methyl methacrylate) nanocomposites. Thermochimica Acta, 435, 202-208. doi:10/1606/j.tca.2005.06.006.

Zhou, C, Si, Q, Aa, Y, Tan, Z, Sun, S, Zhang, M, \& Zhang, H. (2007). Effect of matrix composition on the fracture behaviour of rubber-modified PMMA/PVC blends. Poly Bull, 58, 979-988. doi:10.1007/s00289-006-0710-4.

Zhu, LP, Yi, Z, Liu, F, Wei, XZ, Zhu, BK, \& Xu, YY. (2008). Amphiphilic graft copolymers based on ultrahigh molecular weight poly(styrene-alt-maleic anhydride) with poly (ethylene glycol) side chains for surface modification of polyethersulfone membranes. European Polymer Journal, 44, 1907-1914. doi:10.1016/j.europolymj.2008.03.015.

\section{Submit your manuscript to a SpringerOpen ${ }^{\circ}$ journal and benefit from:}

- Convenient online submission

- Rigorous peer review

- Immediate publication on acceptance

- Open access: articles freely available online

- High visibility within the field

- Retaining the copyright to your article

Submit your next manuscript at springeropen.com 